\title{
Spatial Analysis to Identify Urban Areas with Higher Potential for Social Investment
}

\author{
Marcos Roberto Martines ${ }^{1^{*}}$, Rogério Hartung Toppa ${ }^{2}$, Ricardo Vicente Ferreira ${ }^{3}$, \\ Alexandre Cavagis ${ }^{4}$, Fernando Shinji Kawakubo ${ }^{5}$, Rúbia Gomes Morato ${ }^{5}$ \\ ${ }^{1}$ Department of Geography, Tourism and Humanities, Federal University of São Carlos (UFSCar), Sorocaba, Brazil \\ ${ }^{2}$ Department of Environmental Science, Federal University of São Carlos (UFSCar), Sorocaba, Brazil \\ ${ }^{3}$ Department of Geography, Federal University of Triângulo Mineiro (UFTM), Uberaba, Brazil \\ ${ }^{4}$ Department of Physics, Chemistry and Mathematics, Federal University of São Carlos (UFSCar), Sorocaba, Brazil \\ ${ }^{5}$ Department of Geography, University of São Paulo (USP), São Paulo, Brazil \\ Email: *mmartines@ufscar.br, toppa@ufscar.br, ricardo.ferreira@uftm.edu.br, cavagis@ufscar.br, fsk@usp.br, rubiagm@usp.br
}

How to cite this paper: Martines, M.R., Toppa, R.H., Ferreira, R.V., Cavagis, A., Kawakubo, F.S. and Morato, R.G. (2017) Spatial Analysis to Identify Urban Areas with Higher Potential for Social Investment. Journal of Geographic Information System, 9, 591-603.

https://doi.org/10.4236/jgis.2017.95037

Received: September 10, 2017

Accepted: October 28, 2017

Published: October 31, 2017

Copyright (C) 2017 by authors and Scientific Research Publishing Inc. This work is licensed under the Creative Commons Attribution International License (CC BY 4.0).

http://creativecommons.org/licenses/by/4.0/

\begin{abstract}
There has been great interest on the part of public and private initiatives in knowing the location of urban areas with potential for investments in social resources. The aim of the present article is to propose a methodology to identify such areas, using the city of São Paulo (Brazil) as a case study. This approach, supported by The Geographic Information System (GIS), is based on multicriteria analysis and quantification of spatial data. The results, presented spatially in a synthesis map, made possible to identify promissory areas for social investment in São Paulo. The method allows us to analyze data at different spatial scales from the GIS base, enabling a systematization to find out areas with higher potential for investment in social equipment, services and facilities. Furthermore, it gives possibility of modeling several variables, thus being adaptable to different geographic areas.
\end{abstract}

\section{Keywords}

Urban Social Investment, Spatial Multicriteria Analysis, Geographic Information System

\section{Introduction}

In recent decades, it was possible to see a significant change in the management of companies. In the early twentieth century, the performance of the company was directed to the production, because of the limited competition at that time. The globalization process constitutes a watershed as regards the behavior of the 
corporations in relation to the market. Market integration and the fall of trade barriers have increased the competition among companies throughout the world. In order to take advantage of opportunities arising from the expansion of potential markets, it was necessary to change the business strategies and incorporate issues, such as quality, brand, customer service, product innovation and other key attributes for successful companies [1]. The Nobel Prize in Economics, [2], stated that the only social responsibility of business should be the use of resources and engagement in activities which ensure their profits. This is the expression of the idea that prevailed during this period.

Over the years, the increasing concentration of income and the increase in social problems influence consumers' opinion. They then began to demand, every day more, the adoption of standards of ethical conduct to prioritize the human being, society and the environment. Consequently, companies started to worry about the social legitimacy of their actions. This new paradigm of business activity is deeply related to the guiding principle of the so-called "sustainable development", which foresees that the economic growth must promote social progress and respect for the environment [1]. In this context, increases the practice of corporate social responsibility and, nowadays, the pursuit for excellence by companies should also involve the quality of relations, in addition to economic, social and environmental sustainability [3].

Understanding the spatial distribution of data from phenomena occurring in space is a major challenge for the elucidation of pivotal issues in several areas of knowledge. Beyond the visual perception of the spatial distribution of problems, it is essential to translate the existing patterns into objective and measurable parameters. The emphasis of spatial analyses is to measure properties and correlations, taking into account the spatial location of the phenomenon under study in an explicit way, since economic, social and environmental processes involved in the planning of a given territory are inherently spatial.

The technologies associated to The Geographic Information Systems (GIS) allow us to produce, store, analyze and visualize spatial data, thus having great potential to address planning issues and land management. This spatial planning, such as any other problem related to spatial decision, usually involves a large set of feasible alternatives, besides multiple, conflicting and incommensurable evaluation criteria [4].

Currently, GIS are widely used in almost administration levels, since the methods of geographic information processing are suitable to support the most different planning tasks, regarding the assessment of a factual situation by using a flexible combination of multiple data layers [5]. In this way, the application of GIS, since based on quantitative methods, may be advantageous to guide social investments in urban areas. Importantly, no references have been found in literature about a similar application, reinforcing the unprecedented character of this approach.

According to [6], there has been increasing interest from the Brazilian busi- 
ness community in making social investments, especially because this has been a matter of global concern, which generates discussions on issues related to social management, the implementation of community projects, as well as concepts like "ethical entrepreneur" and "social responsibility". From this perspective, a key issue for the realization of social investments by the private sector or publicprivate partnerships is to understand the geographic distribution of resources and social needs, in order to make the investment more effective. Thus, the main objective of this article is to provide a new insight on these questions, by proposing a spatial solution, based on multicriteria analysis. The methodology employed establishes two fundamental questions for the planning of private social investment: i) Where are located the municipal public facilities and services and how to assign a quantitative indicator, considering the government presence in the area? ii) How to consider, in a quantitative manner, the demand for facilities and services in relation to the social vulnerability?

Therefore, based on the presence of public institutions in a particular administrative area of the city (district, neighborhood), in contrast with the social vulnerability of that territory, the greater or lesser lack of social resources may be evaluated, leading to the identification of areas with greatest potential to investment in equipment, services and facilities for society. According to [7], in a book that brings together works on "The International Seminar for Private Social Investment: Methodologies", the methodological choices are essential so that the assessment processes generate relevant and useful information, regarding the results and impacts of the private social investment. Furthermore, the choice of one or another methodological approach depends upon the objectives and issues, which one wants to address.

To sum up, aiming to contribute to the advancement of methodological proposals for this theme, the objective of this study was to develop a method, based on multicriteria spatial analysis in GIS environment, in order to identify areas with the greatest potential for social investments in the city of São Paulo (Brazil), especially due to the complexity of its municipal context.

Real estate speculation contributes to the increased cost of the most central areas of the city which possesses better infrastructure, making such areas more inaccessible to the large majority of population. Moreover, as the city grows, areas that used to be cheaper and of easier access have become more expensive, thus leading the vast majority of the poor population to search for housing in more distant regions.

In a bibliographic review, we have found works about social vulnerability and social investment, such as from [8] [9] [10] [11] [12] among others. Nevertheless, they deal with the themes independently, without linking to the spatial component. The methodology adopted in this work brings an integrative proposal and establishes a counterpoint between the public infrastructure of the city and the social vulnerability of the population, thus demonstrating the phenomena from the perspective of spatial surfaces, which allows the identification of areas representing the best opportunities for social investments. 


\section{Study Area}

The area selected for application of the proposed method is the city of São Paulo-Brazil-which is one of the largest cities in the world in terms of population, the most urbanized in Brazil. It is the leading global city in South America and is the center of the Brazilian megalopolis, which includes a region that involves many cities including the city of Rio de Janeiro. By owning a complex urban infrastructure, the city of São Paulo is considered the financial center of Brazil, home to headquarters of multinational companies and also the main Brazilian stock exchange, Bovespa.

Among the main social problems of the city, the urban segregation, due to the concentration of income in the central areas of cities, as well as the lack of public planning policies to manage the city sprawl, are important issues which deserve attention. People from segregated regions suffer because of the long distances between their residences and the business centers where they work, and the overwhelming majority is low-wage workers. We also have to include, in this scenario, poor public transport conditions, beyond the lack of infrastructure.

\section{Methods}

\subsection{Definition of Data Matrices}

Two categories of data have been defined as indicators of social investment in urban territory. For each category, different variables have been selected and arranged in two analytical matrices, in order to construct numerical surfaces:

1) Data representing the social vulnerability (matrix 1): We have selected those related to precarious settlements in the city, organized into the following layers: Slums, Tenements and Irregular Allotments. In this case, the proposal of [13] has been adopted to define the concept of "social vulnerability", considering this parameter as the conditions associated with the capacity to confront certain situations of risk, thus referring it as the greater or lesser capacity of an individual, family or social groups to "control the forces that affect their well-being, i.e., the possession or control of assets that constitute the resources required to take advantage of the opportunities offered by the State, market and society." The choice of these elements of the city was based on [14] which features the slums as being part of the fixed structure of cities, not only in Brazil, but also in other countries on the economic periphery. Such locations are still perimeters of poverty and limited social life in the cities [15]. There are other studies of social vulnerability to the city of São Paulo with IDLH (São Paulo Social Vulnerability Index) and IPRS (São Paulo Index of Social Responsibility) but were not used because the data are in the range of census sectors incompatible with our scale of study.

2) Data representing the public infrastructure (matrix 2): Set of existing institutional data on the various public resources in the city, organized into the following layers: Nursery, Pre-School, Basic Health Unit, Elementary School, Secondary School, Vocational Education, Ambulatory Medical Assistance (AMA), 
Library, Youth and Adults Education (YAE), Theatre, Reading Area, Culture House, Museum, Municipal School of Music, School Club and Reading Park.

\subsection{Elaboration of Numerical Surfaces}

The standardization of layers in continuous numerical surfaces was carried outby organizing the different attributes on a common basis, in order to normalize them into the same numerical range $(0-1)$. The normalization of the values was carried out by applying the following expression:

$$
N=x_{i}-\min / \max -\min
$$

where: $N$ is the resulting value from normalization; $x_{i}$ is the recorded value for a given variable; min and max correspond, respectively, to the lowest and highest recorded values of the variable.

Figure 1 illustrates this process by taking as example the layer "Elementary, High and Technical Schools". In Figure 1(A), the points represent the spatial distribution of schools in the city of São Paulo and the Figure 1(B) shows, in the "TOT" column, the total number of classrooms per school unit. The values presented in "NORM" column result from the normalization of the data, which establishes the assignment of the value 1 for the largest amplitude (in this case, the line 1, with 80 classrooms in the school). Conversely, the smaller amplitude corresponds to the zero value. In this manner, the variation of the values in the range of $0-1$ is proportional to the variation of the original data (Figure $1(B)$ ). Applying this same standardization for all layers, a uniform universe of data is created for an integrated analysis, based on the same investigation criteria. Starting from the normalized values, each attribute in the territory is then represented by a numerical model, based on the Kernel density estimator [16] [17] in order to support the development of synthesis maps. The distance parameter to the Kernel estimator was 500 meters, which was based on the Euclidean distances between the geographic event and its environs, on the understanding

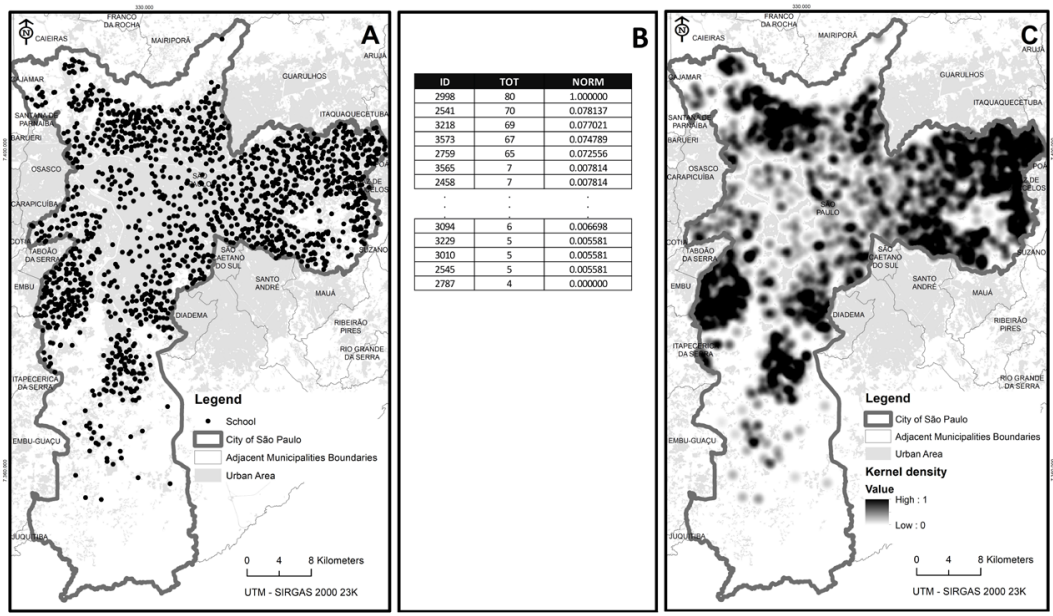

Figure 1. (A) Basic education map; (B) table with absolute and normalized values; (C) density map. 
that such distance is reasonable for walking from home, as an example, to a school or Basic Health Unit (Figure 1(C)).

\subsection{Map Algebra}

Based on the results obtained from the Kernel estimator, an algebraic sum of the numerical surfaces is carried out [18]. Figure 2 illustrates the procedure used in this case.

\subsection{Map Algebra for Estimating the Social Vulnerability}

The numerical synthesis model was generated through the algebraic sum of the layers from the Kernel estimator, in the range from zero to 1, based on the data established in the matrix 1 (Slums, Tenements and Irregular Allotments). The same weight $(\mathrm{P}=1)$ was considered for all layers, giving all the same degree of importance in Equation (1), as follows, which is justified on the premise that the living conditions of the people in those areas are so extreme that it would be extremely difficult attempting to consider the factors related to social vulnerability in a comparative manner.

$$
P I F=P\left(P I_{S}\right)+P\left(P l_{T}\right)+P\left(P I_{A}\right)
$$

where: PIF $=$ Numerical Synthesis Model; $\mathrm{P}=$ Weight; $\mathrm{PI}_{\mathrm{S}}=$ Standard layer (Slums); $\mathrm{Pl}_{\mathrm{T}}=$ Standard Layer (Tenements); $\mathrm{PI}_{\mathrm{A}}=$ Standard Layer (Allotments).

The result of the algebra corresponds to a numerical matrix related to the synthesis map of social vulnerability. In interpreting the results, they shall be deemed values close to 1 as indicatives of higher social vulnerability, while values close to zero represent lower social vulnerability.

Figure 3 shows the result of matrix algebra for social vulnerability; it is possible to identify that there is a radial gradient in the increase of social vulnerability from the center to the periphery. The center-west of the city does not show areas of poverty, on the other hand, in the peripheral direction of the city, a radial increase of social vulnerability indices is observed, with the most critical areas

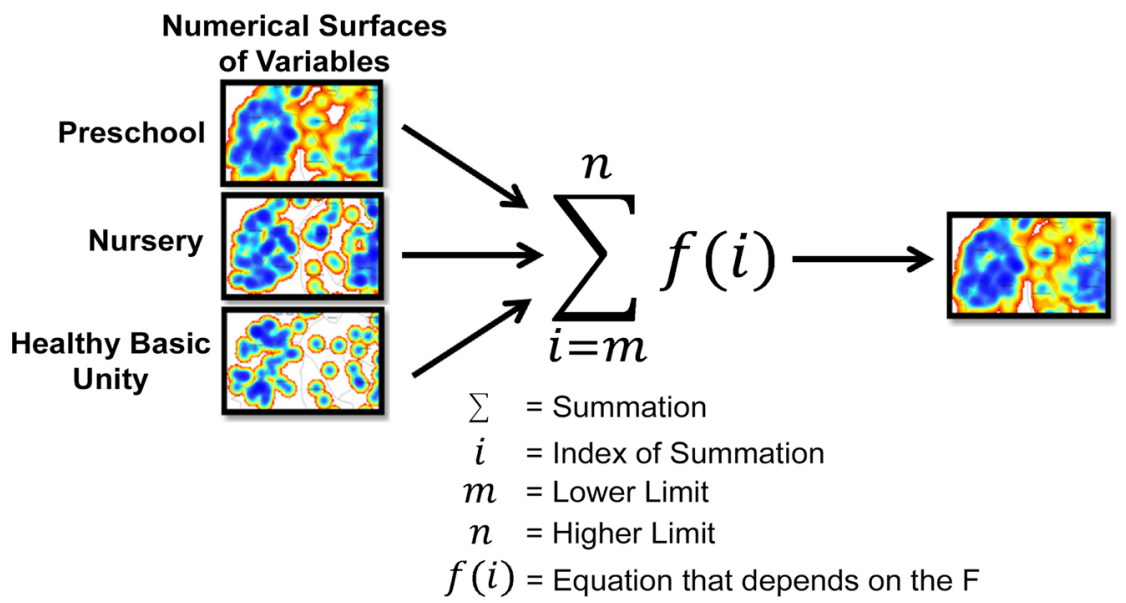

Figure 2. Illustration of the method of algebraic sum of maps. 


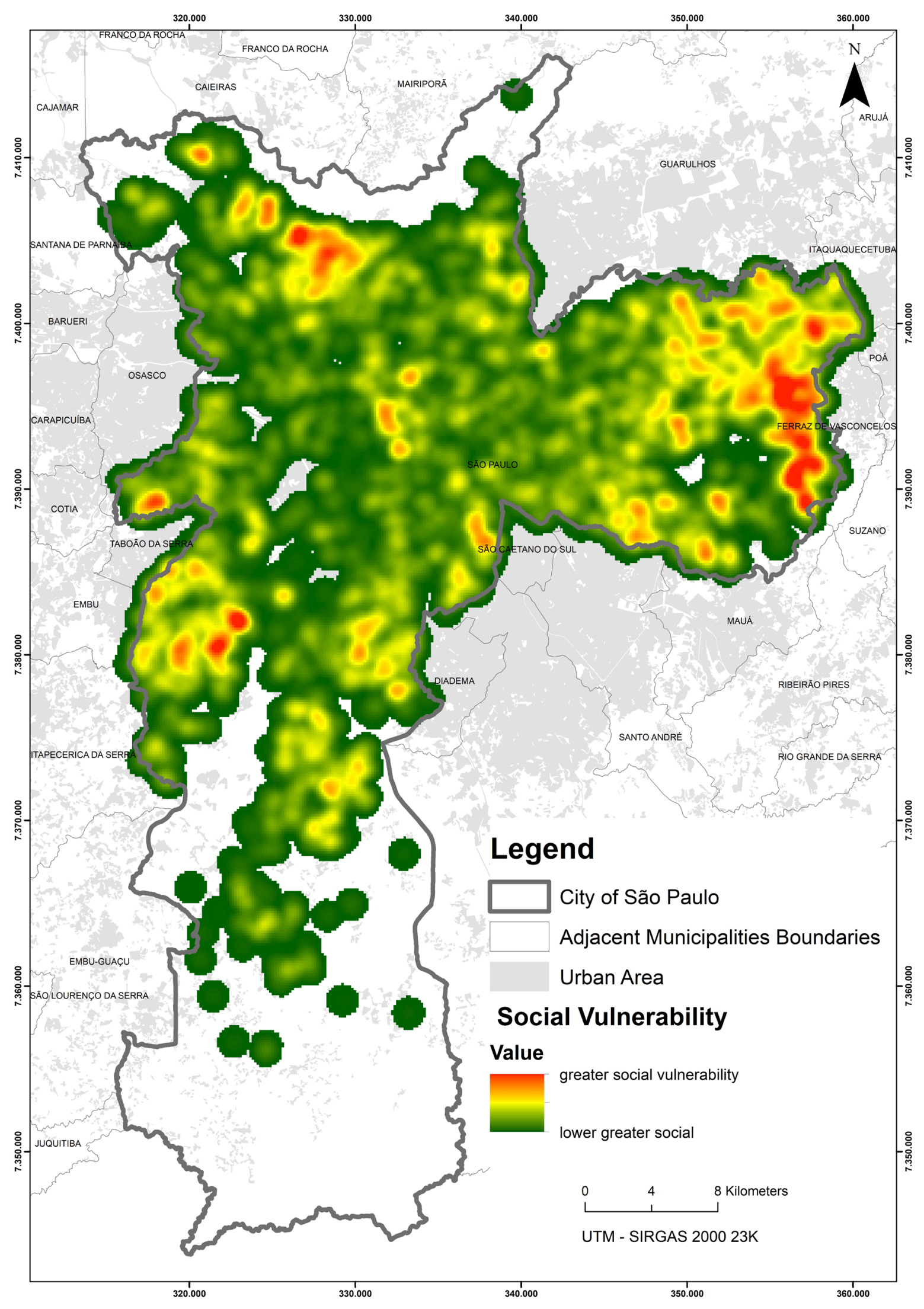

Figure 3. Numerical synthesis model for the social vulnerability. 
highlighted in red. In principle, these poverty concentration regions are obvious candidates for private social investment, however, we have to consider the possibility of those areas have already been receiving investments from the public sector as well. In this way, our goal was to identify critical areas, with little public investment, making the counterpoint between the social vulnerability and the presence of the public sector in the region.

\subsection{Modeling of Public Infrastructure Matrix}

Considering the demand of society for each public resource, it is necessary to establish a ranking of layers to support the development of a numerical model for the presence of public infrastructure in the area. In this way, each layer considered in the map algebra should receive a differentiated weight of importance. To execute this step, it has been adopted the Analytic Hierarchy Process (AHP), which is a procedure for decision-making based on the logic of paired comparison. In this procedure, the diverse factors that influence a particular decision are compared two by two and a criterion of relative importance is attributed to the relation established between these factors, according to a qualitative judgment scale [19]. According to the AHP, it is necessary to establish a hierarchy of layers to generate weights. Figure 4 shows the hierarchy of distributed layers from a higher to a lower importance, which was adopted to develop the method.

From the hierarchical classification and calculations described in the Analytic Hierarchy Process (AHP), weights have been generated for each one of the layers (Table 1).

The use of the AHP leads to an index to assess the consistency of the generated weights. According to [19] the value of this consistency index (CI) should be in the range $0-1$, which means that the judgments to obtain the weights have

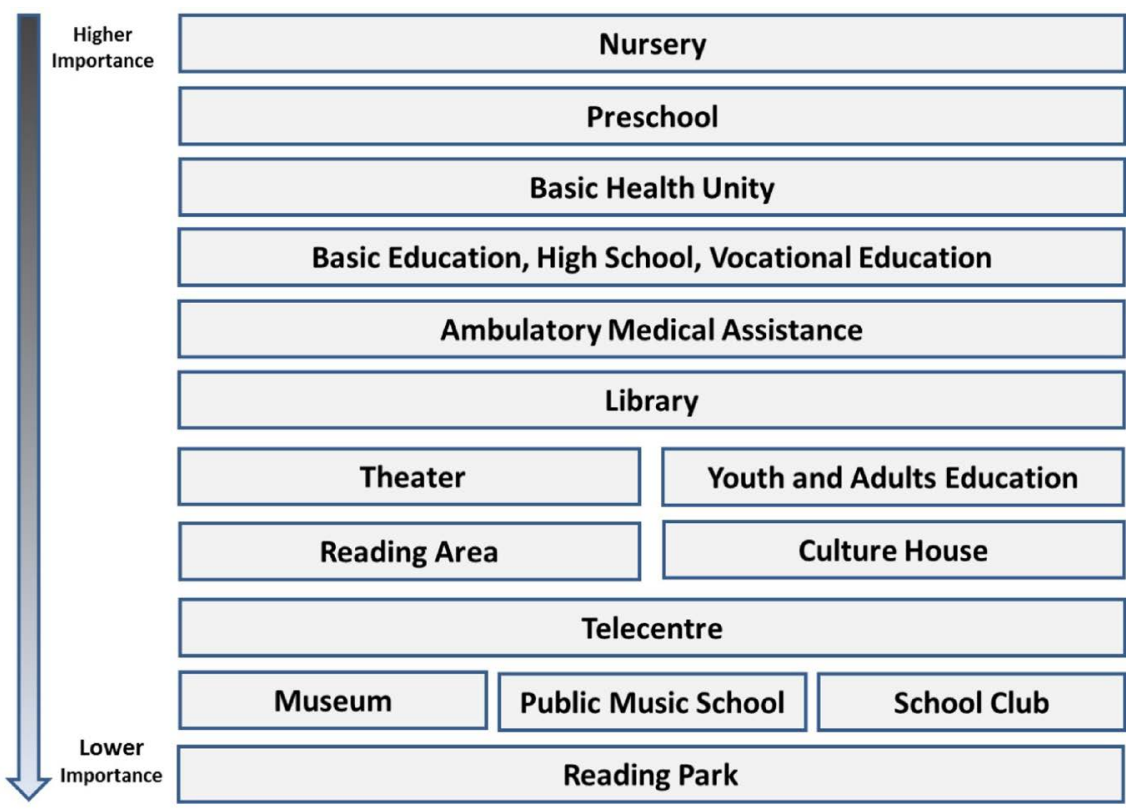

Figure 4. Hierarchy of the public infrastructure matrix. 
Table 1. Weights generated by applying the Analytic Hierarchy Process to the numerical layers of public infrastructure.

\begin{tabular}{|c|c|}
\hline Type of Facility & Weight \\
\hline Nursery & 0.131 \\
\hline Preschool & 0.116 \\
\hline Basic Health Unit (BHU) & 0.102 \\
\hline Elementary and High School & 0.089 \\
\hline Ambulatory Medical Assistance (AMA) & 0.077 \\
\hline Library & 0.066 \\
\hline Theater & 0.057 \\
\hline Youthand Adults Education & 0.057 \\
\hline Reading Area & 0.048 \\
\hline Culture House & 0.048 \\
\hline Telecentres & 0.041 \\
\hline Museum & 0.035 \\
\hline Municipal School of Music & 0.035 \\
\hline School Club & 0.035 \\
\hline CDC (Community School Club) & 0.030 \\
\hline Reading Park & 0.026 \\
\hline Total & 1.000 \\
\hline
\end{tabular}

been properly made. Since the CI value obtained by using the methodology here proposed was 0.67 , it may be inferred that the judgments have also been made in a proper way in the present case study. The numerical synthesis model of public infrastructure was obtained by applying the following expression:

$$
P I F=\sum\left(W^{*} P I\right)
$$

where: PIF = final matrix synthesis; $\mathrm{W}=$ value derived from the application of the AHP; PI = Numerical models normalized.

This model was obtained from the 16 variables that compose the institutional data matrix. The result of the numerical model is presented in Figure 5.

Figure 5 shows the matrix algebra to public infrastructure, which is, in general, well distributed throughout the urban territory, but with concentration of investments in some peripheral areas of the city, highlighted in red on the map.

\subsection{Definition of the Urban Territory for Opportunities of Social Investment}

By using the layers of public infrastructure and social vulnerability, represented as numerical synthesis models on continuous surfaces, a subtraction of these models should be done in order to make possible the mapping of areas with lower presence of public infrastructure over the areas of highest social vulnerability on the urban territory (Figure 6(A)). 


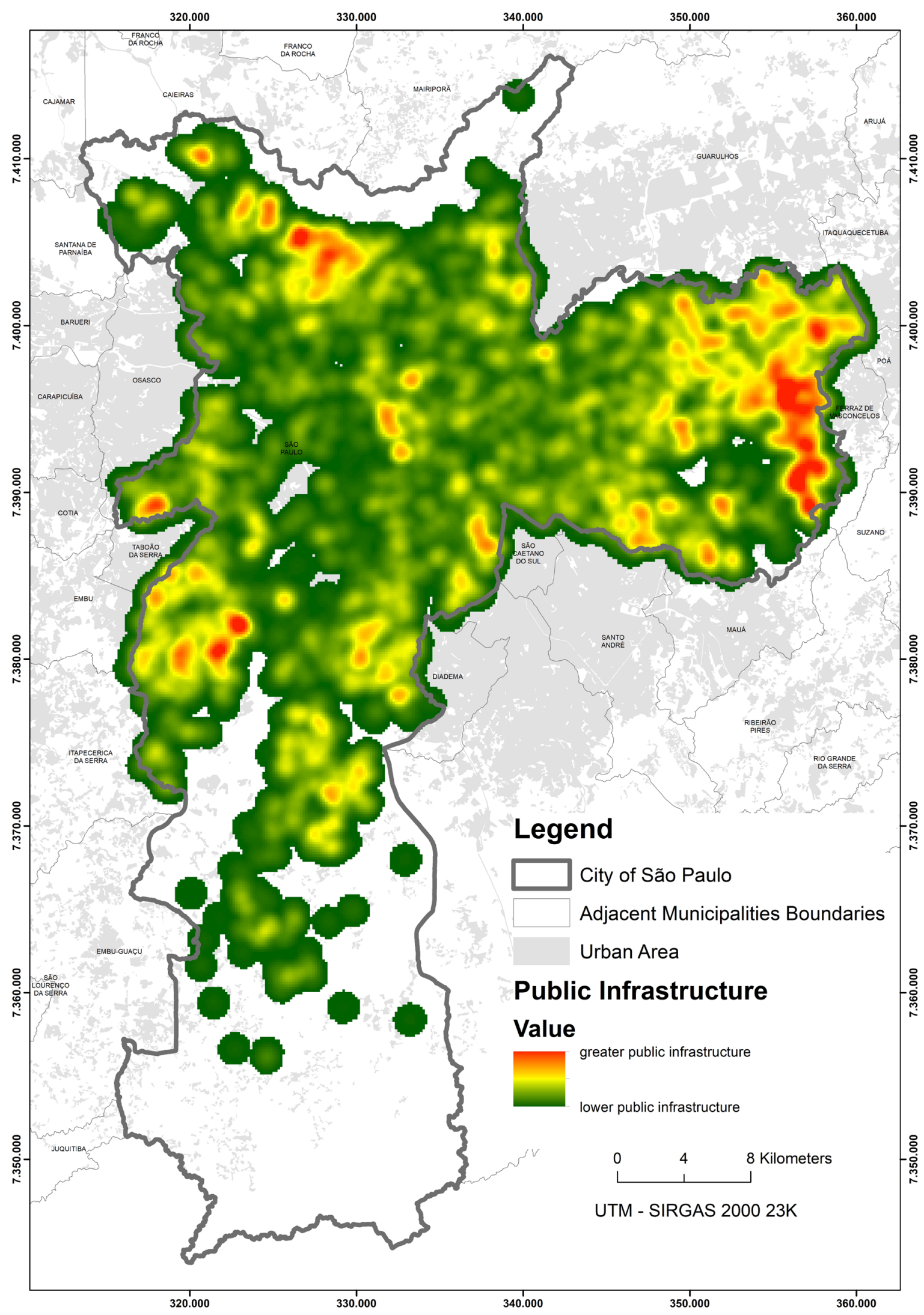

Figure 5. Numerical synthesis model for the public infrastructure data. 


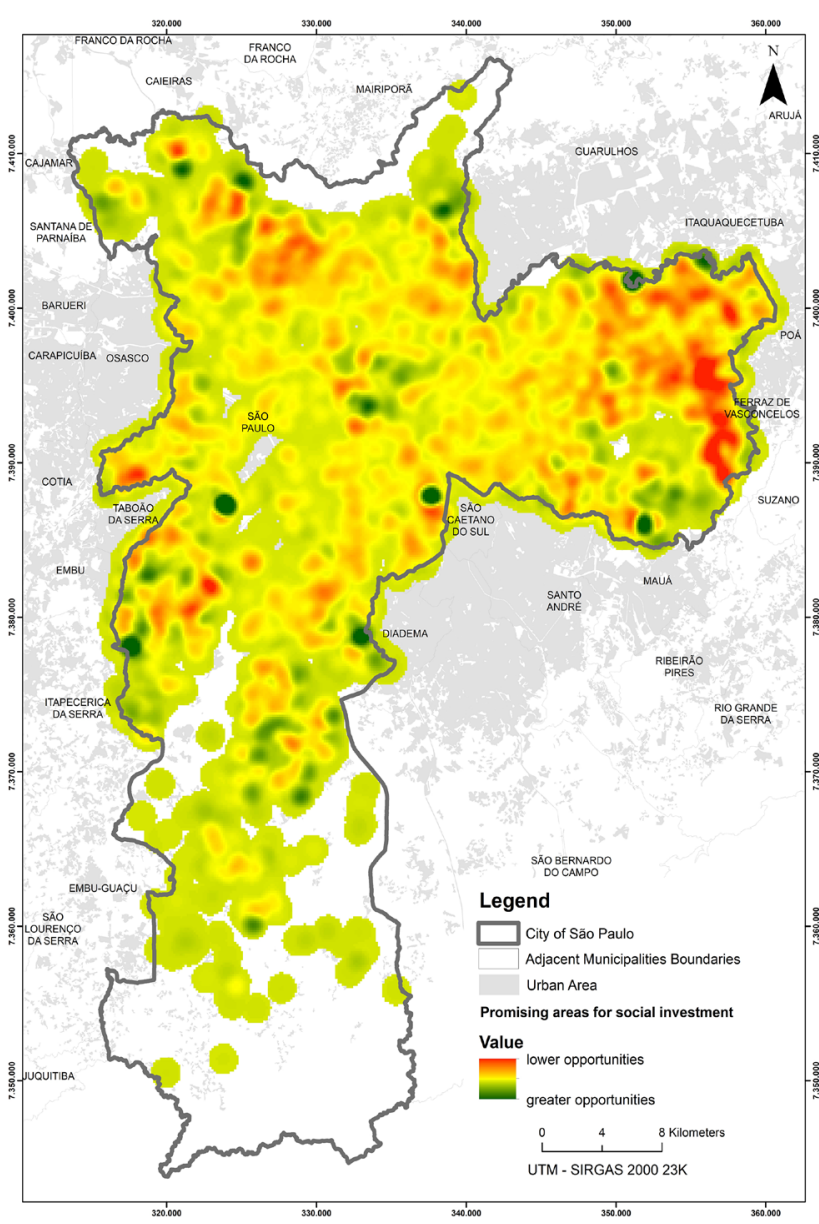

(A)

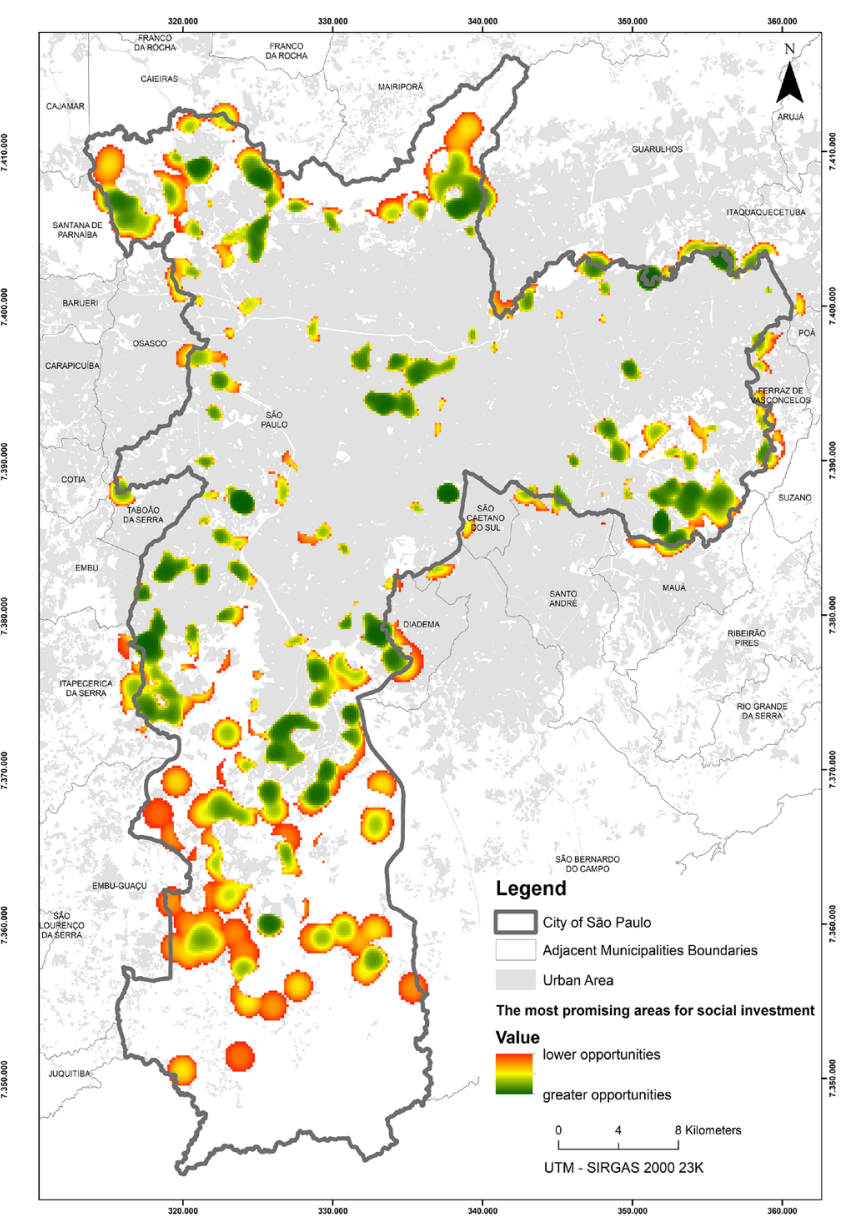

(B)

Figure 6. (A) Promising areas for social investments in São Paulo, determined by subtracting the numerical models of public infrastructure and social vulnerability; (B) a highlight of the most promising areas for social investments in São Paulo.

The interpretation of the results should be based on the idea that all values equal to or greater than zero indicate a greater presence of the public sector in relation to the social vulnerability. Conversely, negative values represent the opposite situation, revealing a public infrastructure deficit. Thus, these latter areas represent opportunities for social investment. As the main objective of this research is to reveal the areas with the greatest potential for private investment, a selection of attributes with negative values was carried out from the numerical model shown in Figure 6(A).

This procedure aims to highlight areas with greatest deficits, since they are the ones which actually represent the most promising areas for private investment throughout the territory. This gradient of negative values is represented on the map of Figure 6(B), by assigning a color variation from green to red, so that the green color refers to the most negative values, which effectively correspond to the greatest opportunities, while the red color refers to values closer to zero, indicating the lowest effective opportunities. Thus, the best real opportunities for private investment are more explicitly highlighted. 


\section{Conclusions}

The methodology described presents an innovation regarding the use of quantitative data referring to social vulnerability and public infrastructure, integrating data matrices in a comprehensive spatial analysis, established through procedures performed in GIS environment. Another significant result of this research was to produce a synthesis map to guide companies about the most disadvantaged areas of the city to receive private social investment, avoiding an overlapping of resources application.

Beyond that, the method allowed to select areas on different analytical scales, from streets to administrative districts, which are promising candidates to receive social investments in order to expand the opportunity levels in these regions. Based on the local reality, the model enables a mapping of areas with greatest potential for investments in the city of São Paulo, taking into account both the available public services and the local vulnerability. Since different variables may be considered in the Analytic Hierarchy Process (AHP), as well as in the identification of socially vulnerable areas, the described methodology might be applied in different geographic areas, using the most diverse spatial scales of analysis.

A challenge to enhance the present model is the availability of geospatial data, in order to improve the accuracy of the proposed methodology, especially about the socioeconomic characteristics of the population. Furthermore, it is of fundamental importance that the public administration and the private sectors of the economy introduce, in their discussions, the possibility of using spatial models as subsidy to drive decisions which have social and urban impacts.

\section{Highlights}

Spatial multicriteria analysis applied to identify promising areas for social investment.

Development of a methodology to guide more efficiently the applications of social resources.

Quantitative and qualitative methods to identify the most suitable areas for urban social investment.

Approach to map the best areas for social investment in São Paulo, one of the largest cities in the world.

\section{References}

[1] Teixeira, L.S. (2004) Corporate Social Responsibility. Legislative Consulting of The Brazilian National Congress, Brasília.

[2] Friedman, M. (1970) The Social Responsibility of Business Is to Increase Its Profits. The New York Times Magazine, 13 September 1970.

http://www.colorado.edu/studentgroups/libertarians/issues/friedman-soc-resp-busi ness.html

[3] Ethos Institute Guide for Tools Compatibility, São Paulo, Ethos, 2014. 
[4] Zhang, Y.J., Li, A.J. and Fung, T. (2012) Using GIS and Multi-Criteria Decision Analysis for Conflict Resolution in Land Use Planning. Procedia Environmental Sciences, 13, 2264-2273. https://doi.org/10.1016/j.proenv.2012.01.215

[5] Lang, S. and Blaschke, T. (2009) Landscape Analysis with GIS. Oficina de Texto, São Paulo, $424 \mathrm{p}$.

[6] Rico, E.M. (2004) Corporate Social Responsibility and the State: An Alliance for Sustainable Development. São Paulo in Perspective, 18, 73-82. http://www.scielo.br/pdf/spp/v18n4/a09v18n4.pdf

[7] Ricomini, V.V., Pinto, M. and Queiroz, E. (2013) Presentation. In: Itaú Social Foundation, Roberto Marinho Foundation, Maria Cecília Souto Vidigal Foundationand Move, Eds., II International Seminar. Evaluation for Private Social Investment: Methodologies, Santillana Foundation, Rio de Janeiro.

http://moderna.com.br/lumis/portal/file/fileDownload.jsp?fileId=8A8A8A824279A CF101427B602DC93A3E

[8] Carley, M.J. (1981) Social Measurement and Social Indicators: Issues of Policy and Theory. Boston, Mass., George Allen \& Unwin, 1981. x, 195 p. (Contemporary Social Research Series, No. 1).

[9] Miles, I. (1985) Social Indicators for Human Development. United Nations University.

[10] McEwin, M. (1995) Social Indicators and Social Statistics in Australia. Statistical Journal of the United Nations Economic Commission for Europe, 12, 309-318.

[11] Morel, N., Palier, B. and Palme, J. (2012) Towards a Social Investment Welfare State? Ideas, Policies and Challenges. Policy Press.

[12] Bouget, D., Frazer, H., Marlier, E., Sabato, S. and Vanhercke, B. (2015) Social Investment in Europe. A Study of National Policies. European Commission, Brussels Google Scholar.

[13] Kaztman, R. (2001) Seduced and Abandoned: The Social Isolation of Urban Poor. Revista de la CEPAL, Santiago do Chile, No. 75, 171-189.

[14] Davis, M. (2006) Planet Slum. Boitempo, São Paulo.

[15] Villaça, F. (2001) The Intra-Urban Space in Brazil. Studio Nobel: FAPESP: Lincoln Institute, São Paulo, 185.

[16] Rosenblatt, M. (1956) Remarks on Some Nonparametric Estimate of a Density Function. The Annals of Mathematical Statistics, 27, 832-837. https://doi.org/10.1214/aoms/1177728190

[17] Parzen, E. (1962) On Estimation of a Probability Density Function and Mode. Annals of Mathematical Statistics, 33, 1065-1076. https://doi.org/10.1214/aoms/1177704472

[18] Tomlinson, R.F. (1990) Geographic Information Systems-A New Frontier. In: Peuquet, D.J. and Marble, D., Eds., Introductory Readings in GIS, Taylor \& Francis, London, 18-29.

[19] Saaty, T.L. (1980) The Analytic Hierarchy Process. McGraw-Hill, New York, 287. 